\title{
Postprandial Metabolism and Vascular Function: Impact of Aging and Physical Activity Level
}

\author{
Nicholas A. Koemel, Christina M. Sciarrillo, Katherine B. Bode, Madison D. Dixon, \\ Edralin A. Lucas, Nathaniel D.M. Jenkins, and Sam R. Emerson \\ Oklahoma State University
}

\begin{abstract}
The consumption of a high-fat meal can induce postprandial lipemia and endothelial dysfunction. The authors assessed the impact of age and physical activity on metabolic and vascular outcomes following meal consumption in healthy adults. The authors recruited four groups: younger active (age $22.1 \pm 1.4$ years; $n=9$ ), younger inactive (age $22.6 \pm 3.7$ years; $n=8$ ), older active (age $68.4 \pm 7.7$ years; $n=8$ ), and older inactive (age $67.7 \pm 7.2$ years; $n=7$ ). The metabolic outcomes were measured at the baseline and hourly for $6 \mathrm{hr}$ post high-fat meal consumption (12 kcal/kg; 63\% fat). Flow-mediated dilation was measured at the baseline, $2 \mathrm{hr}$, and $4 \mathrm{hr}$ postmeal. The total area under the curve for triglycerides was significantly lower in the more active groups, but did not differ based on age (younger active $=6.5 \pm 1.4 \mathrm{mmol} / \mathrm{L} \times 6 \mathrm{hr}$, younger inactive $=11.7 \pm 4.8$, older active $=6.8 \pm 2.7$, older inactive $=12.1 \pm 1.7 ; p=.0004)$. After adjusting for artery diameter, flow-mediated dilation differed between groups at the baseline (younger active $=4.8 \pm 1.6 \%$, younger inactive $=2.5 \pm 0.5$, older active $=3.4 \pm 0.9$, older inactive $=2.2 \pm 0.4 ; p<.001$ ) and decreased significantly across groups $4 \mathrm{hr}$ postmeal (mean difference $=0.82 ; 95 \% \mathrm{CI}[0.02,1.6] ; p=.04$ ). These findings highlight the beneficial effect of regular physical activity on postprandial lipemia, independent of age.
\end{abstract}

Keywords: cardiovascular disease, endothelial dysfunction, flow-mediated dilation, lipemia, triglycerides

Cardiovascular disease (CVD) accounts for $31 \%$ of all deaths globally (Stewart et al., 2017) and exhibits one of the strongest and most comprehensive connections with dietary behavior. Consumption of a single high-fat meal (HFM) results in a deleterious postprandial metabolic state that can include increased oxidative stress and inflammation (Alipour et al., 2008; Devaraj et al., 2008). The adverse metabolic response to an HFM is characterized by significantly elevated plasma triglycerides (TG), known as postprandial lipemia (PPL). The magnitude of this TG response is directly associated with CVD risk (Hyson et al., 2003) and is more strongly associated with CVD risk than fasting TG (Bansal et al., 2007). Given that most individuals likely spend the majority of their day in a postprandial state, PPL represents a more externally valid determinant of CVD risk (Talayero \& Sacks, 2011).

Age and physical activity are critical modifiers of PPL (Freese et al., 2014; Jackson et al., 2012), although most previous studies have investigated their effects separately. In a recent cross-sectional study by Emerson et al. (2018), the impact of both physical activity level and age on PPL were examined in younger active (YA), older active (OA), and older inactive (OI) individuals. The findings from this study suggest that aging and physical activity levels are important independent factors in determining the postprandial TG response. However, this study was limited in that it did not include a younger inactive group, therefore precluding a determination of whether age or physical activity was a more important modifier of PPL. Furthermore, exercise can temporarily increase TG clearance

Koemel, Sciarrillo, Bode, Dixon, Lucas, and Emerson are with the Department of Nutritional Sciences, Oklahoma State University, Stillwater, OK, USA. Jenkins is with the School of Kinesiology, Applied Health and Recreation, Oklahoma State University, Stillwater, OK, USA. Koemel (nick.koemel@okstate.edu) is corresponding author. capacity by increasing lipoprotein lipase activity, while also increasing caloric expenditure (Ghafouri et al., 2015; Peddie et al., 2012). Conversely, aging is commonly associated with a lower energy expenditure, reduced lipolytic activity of muscle tissue, and an increase in body fat, which can exaggerate PPL (Blaak et al., 1999; Cree et al., 2004; Katsanos, 2014).

Vascular function is another CVD risk indicator that is modified by nutrition, physical activity, and aging (Vogel, 1997). Vascular function is a logical diagnostic tool, given its vital role in maintaining physiological homeostasis and its association with CVD risk (Halcox et al., 2002). However, little is known about how age and physical activity modify vascular function after an HFM. To our knowledge, no previous studies have investigated the postprandial vascular function response to an HFM in younger versus older individuals with different physical activity levels.

Therefore, the purpose of this study was to determine the impact of age and physical activity level on postprandial metabolic outcomes and vascular function. To accomplish this aim, we assessed fasting and postprandial metabolic and vascular responses in groups that differed by age and physical activity level: YA, younger inactive (YI), OA, and OI adults. A secondary purpose was to explore driving factors, such as body composition and glucose control, that may influence postprandial metabolism and vascular function.

\section{Participants and Methods}

\section{Participants}

The participants were recruited based on age (younger 18-35 years; older $\geq 60$ years) and physical activity level (i.e., active and inactive). Each participant was thoroughly interviewed to determine their normal exercise habits. The participants were classified as active 
if they met physical activity guidelines (Piercy et al., 2018), which were defined as $\geq 150$ min per week of moderate-intensity physical activity or $\geq 75$ min per week of vigorous-intensity physical activity, or some equivalent combination. Individuals were classified as inactive if they did not meet the physical activity guidelines and engaged in $<30 \mathrm{~min}$ of planned exercise each week. The participants were also excluded from the study if their physical activity habits had changed significantly within the past 5 years. To assess dietary habits, each participant completed a 3-day food diary the week prior to the assessment, including two weekdays and one weekend day. A medical history questionnaire was also administered to ensure that the individuals did not have any ongoing chronic disease, were not currently taking lipid-lowering or hypertensive medication, and were not consuming tobacco products. This study was approved by and conducted in accordance with the guidelines and regulations of Oklahoma State University's Institutional Review Board and conducted in accordance with the Declaration of Helsinki. Informed consent was obtained in writing from each participant prior to the initiation of the study.

\section{Initial Assessment}

The individuals recruited for this study completed an initial assessment to record anthropometrics, complete questionnaires, and receive experimental instruction. Weight and body composition were assessed using a combination digital scale and bioelectrical impedance analyzer, which has a $97 \%$ accuracy for muscle mass and 80-81\% for visceral adiposity (VAT) detection when compared with magnetic resonance imaging (Seca mBCA 514; Seca GmbH, Hamburg, Germany; Bosy-Westpahl et al., 2017). Height was measured via stadiometer (Seca 213 portable stadiometer; Seca GmbH, Hamburg, Germany). Afterward, each participant wore a wrist-based accelerometer (wGT3X-BT; ActiGraph LLC, Pensacola, FL) for 5 days of the week prior to the main assessment to measure steps per day prior to their meal tolerance test.

\section{Meal Tolerance Test}

The participants selected a time to begin the meal tolerance test between 05:00 and 09:00. The participants were instructed to refrain from exercise for $48 \mathrm{hr}$ prior to their test and caffeine consumption on the day of the experiment. The participants were given a small prepackaged snack (peanut butter crackers, $230 \mathrm{kcal}$, Snyder's-Lance, Inc., Charlotte, NC) to consume prior to initiating a 10-hr fast in order to ensure that all participants were similarly fasted prior to the HFM.

Upon arriving in the laboratory, an indwelling 24-gauge safelet catheter (Exel International, Co., Redondo Beach, CA) was inserted into a forearm vein, and a slow infusion of $0.9 \%$ $\mathrm{NaCl}$ was initiated. A baseline venous blood sample was collected, after which, the HFM was given to the participant, with a completion time limit of $20 \mathrm{~min}$. We chose to use chocolate pie as our HFM to reflect a realistic food item (Marie Callender's chocolate satin pie, Conagra Brands, Omaha, NE; 12 kcal/kg bodyweight; $63 \%$ fat, and $34 \%$ carbohydrate). Serial venous blood draws were taken from the IV catheter each hour to measure postprandial TG, glucose (Glu), total cholesterol (Total-C), high-density lipoprotein cholesterol (HDL-C), and low-density lipoprotein cholesterol (LDL-C) via Cholestech LDX analyzer (Alere Cholestech, San Diego, CA). In the baseline/fasting blood sample only, hemoglobin A1C (HbA1c) was measured in whole blood via DCA Vantage analyzer (Siemens, Boston, MA).

\section{Vascular Function}

Vascular function was assessed using flow-mediated dilation (FMD). This technique incorporates temporary distal occlusion of a limb to elicit a dilatory response (Celermajer et al., 1992). This experiment used the brachial artery for dilatory examination and the wrist as the distal occlusion site. The participants were instructed to lie in a supine position for $15 \mathrm{~min}$ in a darkened area to normalize to the room conditions. A Doppler ultrasound and a $12 \mathrm{MHz}$ probe (Mindray Z5 Ultrasound System; Mindray, Mahwah, NJ) were used to gain a longitudinal view of the brachial artery. After the baseline recording for $2 \mathrm{~min}$, an occlusion pressure of $50 \mathrm{mmHg}$ greater than the participant's systolic blood pressure was applied for $4 \mathrm{~min}$. The pressure was then released, and video of the brachial artery hyperemic response was recorded for an additional $4 \mathrm{~min}$. We used continuous wall tracking, edge detection software to analyze the vessel diameter continuously during recorded videos (Cardio Suite, Quipu, Pisa, Italy). The FMD was reported as the percentage change $(\%)$ in brachial artery diameter from the baseline to the maximum dilation after the cuff pressure is released. FMD was conducted at the baseline (fasting), $2 \mathrm{hr}$, and $4 \mathrm{hr}$ post HFM (Figure 1).

\section{Statistical Analyses}

Using mean differences and $S D$ s from a previous cross-sectional study from our laboratory (Emerson et al., 2018), we estimated that at least 6 individuals per group would be necessary to detect differences in TG tAUC. In this prior study, we detected significant group differences with $n=7-8$ per group. With regard to vascular function, we selected a minimum necessary difference (between groups or in response to the meal) of $4 \%$ for FMD, with an estimated $S D$ of $2 \%$, based on previous studies (Marchesi et al., 2000; Pierce et al., 2011). This resulted in the minimum necessary sample size of seven per group. For the metabolic outcomes, we calculated both tAUC and the incremental area under the curve (iAUC) responses. The tAUC represents the total response for the entire 6-hr postprandial period, while the iAUC represents the total relative change from the baseline/fasting during the postprandial period. We also determined the peak concentration for each metabolic outcome, as well as the time in the postprandial period at which the peak occurred. A one-way analysis of variance (ANOVA) was used to determine group differences. Similarly, analysis of covariance (ANCOVA) was used to analyze PPL while controlling for the influence of the average steps per day for the 2 days preceding the meal tolerance test. For metabolic outcomes and FMD, a two-way (Group $\times$ Time) repeated-measures ANOVA was used to test for time-course interactions between groups in the postprandial period. A one-way and two-way analysis of FMD measurements were allometrically scaled to the baseline brachial artery diameter and the peak brachial artery diameter (Atkinson et al., 2013). Tukey's post hoc adjustment was utilized if main effects were found. No additional correction was conducted for

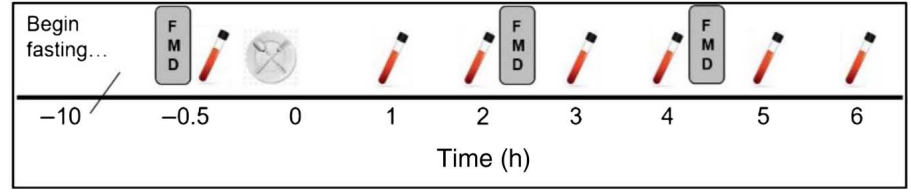

Figure 1 - Hourly metabolic and vascular function data collection timeline. FMD = flow-mediated dilation. 
familywise error rate or a false discovery rate. Partial correlations were used to assess the association between body composition and glucose control with metabolic and vascular outcomes while adjusting for age and physical activity level. A Bonferroni correction was manually applied to the partial correlation analysis to adjust for multiple comparisons by dividing $\alpha=.05$ by the number of comparisons made (35). Thus, a $p$ value of $<.0014$ was considered statistically significant for partial correlations. Otherwise, an $\alpha$ level of .05 was used to determine statistical significance. The ANOVA analyses were conducted in GraphPad Prism (version 7; GraphPad Software, Inc., La Jolla, CA). Partial correlations and ANCOVA analyses were conducted using SPSS statistics for Windows (version 24.0; IBM Corp., Armonk, NY).

\section{Results}

\section{Participant Characteristics}

The participant characteristics are shown in Table 1. Significant group effects were observed for age, body mass index, body fat percentage, VAT, and HbA1c. YA and YI were younger than OA and OI $(p<.0001)$. YA had lower body mass index compared with OI $(p=.007)$. The body fat percentage was different between groups, wherein YA had a lower body fat percentage compared with OA $(p=.0002)$ and OI $(p<.0001)$; YI had a lower body fat percentage than OA $(p=.02)$ and OI $(p=.0002)$. These findings were similar when comparing visceral adipose tissue between groups. YA was lower than OA $(p=.04)$ and OI $(p=.0004)$; YI was lower than OI $(p=.0013)$. Skeletal muscle mass $(\mathrm{SMM}) \mathrm{did}$ not differ between groups. There was a significant group effect for HbA1c, where YI was lower than OA $(p=.009)$ and OI $(p=.048)$. The test meal energy (kcal) did not differ between groups $(p=.11)$.

Recent physical activity, measured in steps per day, was significantly different between groups, where the active groups had more steps per day than the inactive groups. YA was more active than YI $(p=.03)$ and OI $(p=.03)$, while OA was more active than OI ( $p=.0495)$. However, steps per day did not differ between groups for the 2 days prior to the HFM ( 2 days prior, $p=.17 ; 1$ day prior, $p=.45$ ).

The 3-day food record revealed no significant group differences in total calories $(p=.54)$, total fat $(p=.89)$, saturated fat $(p=.69)$, protein $(p=.93)$, carbohydrates $(p=.08)$, fiber $(p=.34)$, sodium $(p=.92)$, or sugar $(p=.66)$.

\section{Fasting Metabolic Outcomes}

The fasting metabolic outcomes are shown in Table 1. There was a significant difference between groups in fasting TG $(p=.02)$. YI had significantly greater fasting TG than OA $(p=.04)$. One-way ANCOVA controlling for 2-day step average preceding the HFM similarly revealed group differences in fasting TG $(p=.02)$. There were no differences between groups for fasting Glu $(p=.32)$. A significant group effect was observed for fasting Total-C $(p=.03)$. Fasting Total-C was lower in YA compared with OI $(p=.02)$. A significant group effect was also observed for LDL-C $(p=.01)$. YA had a lower fasting LDL-C compared with OI $(p=.01)$. There were no differences between groups in fasting HDL-C.

\section{Postprandial Metabolic Responses}

The postprandial metabolic outcomes are presented in Table 2 and Figure 2. There was a significant Group $\times$ Time interaction for the postprandial TG response $(p<.0001)$. YA had a lower TG peak compared with YI $(p=.02)$ and OI $(p=.02)$. Similarly, OA had a lower TG peak compared with YI $(p=.03)$ and OI $(p=.02)$. The TG time to peak was significantly different between groups $(p=.02)$, but there were no significant post hoc comparisons between groups. TG tAUC was significantly different in YA versus YI $(p=.007)$, YA versus OI $(p=.004)$, YA versus OA $(p=.01)$, and OA versus OI $(p=.008)$. TG iAUC was lower in YA versus YI $(p=.02)$, YA versus OI $(p=.005)$, and OA versus OI $(p=.03)$. ANCOVA controlling for 2-day step average preceding the HFM

\section{Table 1 Participant Characteristics and Fasting Metabolic Outcomes}

\begin{tabular}{|c|c|c|c|c|c|}
\hline & $\begin{array}{c}\text { Younger active } \\
n=9\end{array}$ & $\begin{array}{c}\text { Younger inactive } \\
\qquad n=8\end{array}$ & $\begin{array}{c}\text { Older active } \\
\quad n=8\end{array}$ & $\begin{array}{c}\text { Older inactive } \\
n=7\end{array}$ & $p$ value \\
\hline $\operatorname{Sex}(\mathrm{F} / \mathrm{M})$ & $4 / 5$ & $3 / 5$ & $4 / 4$ & $5 / 2$ & \\
\hline Age (years) & $22.1 \pm 1.4^{\mathrm{a}}$ & $22.6 \pm 3.7^{\mathrm{a}}$ & $68.4 \pm 7.7^{\mathrm{b}}$ & $67.7 \pm 7.2^{\mathrm{b}}$ & $<.0001$ \\
\hline BMI $\left(\mathrm{kg} / \mathrm{m}^{2}\right)$ & $23.8 \pm 2.7^{\mathrm{a}}$ & $25.7 \pm 3.7^{\mathrm{a}, \mathrm{b}}$ & $28.2 \pm 3.4^{\mathrm{a}, \mathrm{b}}$ & $30.4 \pm 4.9^{\mathrm{b}}$ & .008 \\
\hline Body fat (\% total mass) & $15.1 \pm 4.6^{\mathrm{a}}$ & $18.9 \pm 2.8^{\mathrm{a}}$ & $27.8 \pm 7.1^{\mathrm{b}}$ & $32.87 \pm 5.7^{\mathrm{b}}$ & $<.0001$ \\
\hline Visceral adipose tissue $(\mathrm{kg})$ & $0.48 \pm 0.37^{\mathrm{a}}$ & $0.61 \pm 0.55^{\mathrm{a}}$ & $1.44 \pm 0.59^{\mathrm{b}}$ & $2.16 \pm 1.20^{\mathrm{b}}$ & .0002 \\
\hline Skeletal muscle mass $(\mathrm{kg})$ & $26.9 \pm 6.4$ & $24.9 \pm 11.3$ & $24.0 \pm 5.3$ & $23.8 \pm 8.6$ & .85 \\
\hline HbA1c $(\%)$ & $5.36 \pm 0.25^{\mathrm{a}, \mathrm{b}}$ & $5.14 \pm 0.36^{\mathrm{a}}$ & $5.69 \pm 0.24^{\mathrm{b}}$ & $5.51 \pm 0.39^{\mathrm{a}, \mathrm{b}}$ & .008 \\
\hline Steps per day & $12,935 \pm 3,216^{\mathrm{a}}$ & $8,498 \pm 2,655^{\mathrm{b}, \mathrm{c}}$ & $12,232 \pm 3,373^{\mathrm{ab}}$ & $8,059 \pm 2,719^{c}$ & .005 \\
\hline Test meal energy (kcal) & $839.8 \pm 11.1$ & $904.2 \pm 145.3$ & $957.8 \pm 133.6$ & $1,036.0 \pm 235.6$ & .11 \\
\hline $\mathrm{TG}(\mathrm{mmol} / \mathrm{L})$ & $0.7 \pm 0.2^{\mathrm{a}, \mathrm{b}}$ & $1.1 \pm 0.5^{\mathrm{a}}$ & $0.7 \pm 0.2^{\mathrm{b}}$ & $1.0 \pm 0.1^{\mathrm{a}, \mathrm{b}}$ & .02 \\
\hline Glu (mmol/L) & $4.8 \pm 0.2$ & $4.7 \pm 0.3$ & $5.0 \pm 0.5$ & $5.0 \pm 0.2$ & .32 \\
\hline Total-C (mmol/L) & $3.9 \pm 0.7^{\mathrm{a}}$ & $4.4 \pm 1.2^{\mathrm{a}, \mathrm{b}}$ & $4.6 \pm 1.0^{\mathrm{a}, \mathrm{b}}$ & $5.4 \pm 0.7^{b}$ & .03 \\
\hline LDL-C (mmol/L) & $2.2 \pm 0.6^{\mathrm{a}}$ & $2.5 \pm 0.8^{\mathrm{a}, \mathrm{b}}$ & $2.7 \pm 0.9^{\mathrm{a}, \mathrm{b}}$ & $3.6 \pm 0.8^{\mathrm{b}}$ & .01 \\
\hline $\mathrm{HDL}-\mathrm{C}(\mathrm{mmol} / \mathrm{L})$ & $1.4 \pm 21.7$ & $1.3 \pm 0.4$ & $1.3 \pm 0.3$ & $1.4 \pm 0.3$ & .99 \\
\hline
\end{tabular}

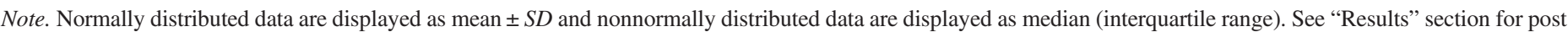

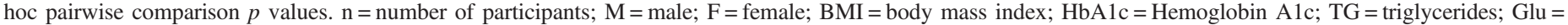

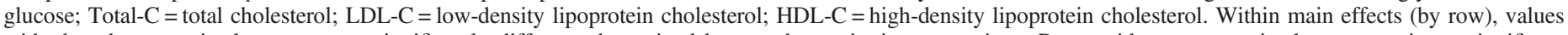

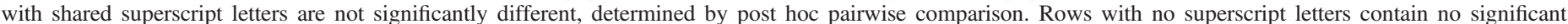
differences. 
Table 2 Postprandial Metabolic Outcomes

\begin{tabular}{|c|c|c|c|c|c|}
\hline & $\begin{array}{c}\text { Younger active } \\
n=9\end{array}$ & $\begin{array}{c}\text { Younger inactive } \\
n=8\end{array}$ & $\begin{array}{c}\text { Older active } \\
n=8\end{array}$ & $\begin{array}{c}\text { Older inactive } \\
n=7\end{array}$ & $p$ value \\
\hline \multicolumn{6}{|l|}{ TG } \\
\hline Peak (mmol/L) & $1.5 \pm 0.4^{\mathrm{a}}$ & $2.6 \pm 1.1^{\mathrm{b}}$ & $1.5 \pm 0.7^{\mathrm{a}}$ & $2.6 \pm 0.5^{\mathrm{b}}$ & .002 \\
\hline Time to peak (hr) & $3.2 \pm 1.5$ & $3.1 \pm 0.8$ & $4.5 \pm 0.9$ & $4.3 \pm 0.5$ & .02 \\
\hline tAUC $(\mathrm{mmol} / \mathrm{L} \times 6 \mathrm{hr})$ & $6.5 \pm 1.4^{\mathrm{a}}$ & $11.7 \pm 4.8^{\mathrm{b}}$ & $6.8 \pm 2.7^{\mathrm{a}}$ & $12.1 \pm 1.7^{\mathrm{b}}$ & .0004 \\
\hline iAUC $(\mathrm{mmol} / \mathrm{L} \times 6 \mathrm{hr})$ & $2.1 \pm 1.7^{\mathrm{a}}$ & $5.1 \pm 2.8^{\mathrm{b}, \mathrm{c}}$ & $2.8 \pm 1.8^{\mathrm{a}, \mathrm{b}}$ & $5.9 \pm 1.5^{\mathrm{c}}$ & .002 \\
\hline \multicolumn{6}{|l|}{ Glu } \\
\hline Peak (mmol/L) & $5.3 \pm 0.6$ & $5.4 \pm 0.4$ & $5.9 \pm 0.6$ & $6.1 \pm 0.9$ & .05 \\
\hline Time to peak (hr) & $1.9 \pm 1.9$ & $2.9 \pm 2.3$ & $2.0 \pm 1.5$ & $2.4 \pm 1.7$ & .71 \\
\hline tAUC $(\mathrm{mmol} / \mathrm{L} \times 6 \mathrm{hr})$ & $27.5 \pm 3.0^{\mathrm{a}}$ & $28.9 \pm 1.5^{\mathrm{a}, \mathrm{b}}$ & $31.2 \pm 3.5^{\mathrm{b}}$ & $32.2 \pm 2.5^{\mathrm{b}}$ & .008 \\
\hline iAUC $(\mathrm{mmol} / \mathrm{L} \times 6 \mathrm{hr})$ & $-1.1 \pm 3.3$ & $0.5 \pm 2.2$ & $1.5 \pm 2.3$ & $2.0 \pm 2.2$ & .09 \\
\hline \multicolumn{6}{|l|}{ Total-C } \\
\hline Peak (mmol/L) & $4.2 \pm 0.8^{\mathrm{a}}$ & $4.8 \pm 1.4^{\mathrm{a}, \mathrm{b}}$ & $4.8 \pm 1.0^{\mathrm{a}, \mathrm{b}}$ & $5.9 \pm 0.5^{\mathrm{b}}$ & .01 \\
\hline Time to peak (hr) & $3.2 \pm 1.9^{\mathrm{a}}$ & $4.1 \pm 1.6^{\mathrm{a}, \mathrm{b}}$ & $2.3 \pm 2.0^{\mathrm{a}}$ & $5.4 \pm 0.8^{\mathrm{b}}$ & .007 \\
\hline tAUC $(\mathrm{mmol} / \mathrm{L} \times 6 \mathrm{hr})$ & $23.4 \pm 4.6^{\mathrm{a}}$ & $27.4 \pm 7.6^{\mathrm{a}, \mathrm{b}}$ & $27.2 \pm 6.1^{\mathrm{a}, \mathrm{b}}$ & $33.7 \pm 3.5^{\mathrm{b}}$ & .01 \\
\hline iAUC $(\mathrm{mmol} / \mathrm{L} \times 6 \mathrm{hr})$ & $0.1 \pm 1.2$ & $1.1 \pm 2.0$ & $-0.2 \pm 1.0$ & $1.3 \pm 1.0$ & .11 \\
\hline \multicolumn{6}{|l|}{ LDL-C } \\
\hline Peak (mmol/L) & $2.3 \pm 0.6^{\mathrm{a}}$ & $2.8 \pm 1.0^{\mathrm{a}, \mathrm{b}}$ & $3.1 \pm 1.0^{\mathrm{a}, \mathrm{b}}$ & $3.7 \pm 0.6^{\mathrm{b}}$ & .01 \\
\hline Time to peak (hr) & $1.0(0.0$ to 4.0$)$ & $1.0(0.3$ to 5.8$)$ & $0.5(0.0$ to 2.5$)$ & $2.0(0.0$ to 4.0$)$ & .57 \\
\hline tAUC $(\mathrm{mmol} / \mathrm{L} \times 6 \mathrm{hr})$ & $12.0 \pm 3.3^{\mathrm{a}}$ & $14.2 \pm 5.0^{\mathrm{a}, \mathrm{b}}$ & $16.0 \pm 5.3^{\mathrm{a}, \mathrm{b}}$ & $20.1 \pm 4.1^{\mathrm{b}}$ & .01 \\
\hline iAUC $(\mathrm{mmol} / \mathrm{L} \times 6 \mathrm{hr})$ & $-1.2(-6.0$ to 0.9$)$ & $-1.1(-4.2$ to 4.0$)$ & $0.01(-4.4$ to 9.1$)$ & $-1.3(-3.1$ to -0.3$)$ & .78 \\
\hline \multicolumn{6}{|l|}{ HDL-C } \\
\hline Peak (mmol/L) & $1.5 \pm 0.6$ & $1.4 \pm 0.3$ & $1.5 \pm 0.2$ & $1.5 \pm 0.4$ & .96 \\
\hline Time to peak (hr) & $3.6 \pm 1.9$ & $2.9 \pm 2.2$ & $2.4 \pm 1.4$ & $2.3 \pm 2.5$ & .57 \\
\hline tAUC $(\mathrm{mmol} / \mathrm{L} \times 6 \mathrm{hr})$ & $8.3 \pm 3.2$ & $7.8 \pm 2.7$ & $8.0 \pm 1.5$ & $7.9 \pm 1.8$ & .98 \\
\hline $\mathrm{iAUC}(\mathrm{mmol} / \mathrm{L} \times 6 \mathrm{hr})$ & $0.1 \pm 0.9$ & $-0.2 \pm 0.5$ & $-0.009 \pm 0.6$ & $-0.3 \pm 0.6$ & .73 \\
\hline
\end{tabular}

Note. Normally distributed data are displayed as mean $\pm S D$, and nonnormally distributed data are displayed as median (interquartile Range). A one-way ANOVA for parametric data and a Kruskal-Wallis test for nonparametric data were conducted to test for differences between groups. The $p$ value column denotes main effects between groups assessed via one-way ANOVA or Kruskal-Wallis test. Within main effects (by row), values with shared superscript letters are not significantly different, determined by post hoc pairwise comparisons. Rows with no superscript letters present contain no significant differences. See "Results" section for post hoc pairwise comparison $p$ values. tAUC $=$ total area under the curve; $\mathrm{AAUC}=$ incremental area under the curve; $\mathrm{ANOVA}=$ analysis of variance; $\mathrm{TG}=$ triglycerides; $\mathrm{Glu}=\mathrm{glucose} ; \mathrm{Total}-\mathrm{C}=$ total cholesterol; LDL-C = low-density lipoprotein cholesterol; HDL-C = high-density lipoprotein cholesterol.

revealed similar findings for postprandial TG with regard to group and time effects (group effect, $p<.001$; time effect, $p<.001$ ). However, the Group $\times$ Time interaction for the postprandial TG was eliminated $(p=.35)$.

The postprandial Glu response had no significant Group $\times$ Time interaction $(p=.59)$ or time effect $(p=.18)$. However, there was a significant group effect $(p=.007)$. Specifically, YA was lower than OA $(p=.04)$ and OI $(p=.01)$ across the entire postprandial period. YA had a lower Glu tAUC compared with OA $(p=.04)$ and OI $(p=.01)$. There were no other significant differences in Glu tAUC or iAUC.

There was no significant Group $\times$ Time interaction for postprandial Total-C $(p=.07)$. However, there were significant time $(p=.04)$ and group $(p=.01)$ effects. Peak Total-C was lower in YA compared with OI $(p=.007)$. There were no significant differences in peak Total-C. The total-C tAUC was lower in YA versus OI $(p=.006)$. The Total-C iAUC was not significantly different between groups.

There was no Group $\times$ Time interaction detected in postprandial LDL-C $(p=.74)$, although there were significant time $(p=.002)$ and group $(p=.009)$ effects. YA had a lower peak postprandial LDL-C compared with OI $(p=.008)$. However, there were no group differences in LDL-C time to peak. LDL-C tAUC was lower in YA versus OI $(p=.006)$. There were no group differences in LDLC iAUC.

Regarding HDL-C, two-way repeated-measures ANOVA revealed no significant Group $\times$ Interaction $(p=.43)$, time effect $(p=.21)$, or group effect $(p=.98)$. There were no significant differences in HDL-C peak, time to peak, tAUC, or iAUC.

\section{Vascular Function}

Postprandial vascular function is shown in Figure 3. There was a significant time effect $(p=.008)$, but there was no group effect $(p=.06)$ or Group $\times$ Time effect $(p=.08)$. One-way ANOVA detected a significant difference between groups in BL (baseline) FMD $(\mathrm{YA}=4.9 \pm 1.3, \mathrm{YI}=3.6 \pm 0.4, \mathrm{OA}=3.6 \pm 1.1, \mathrm{OI}=3.5 \pm$ $0.6 ; p=.002)$. YA exhibited greater FMD compared with YI $(p=.02)$ and OI $(p=.002)$. When analyzing all groups together, there was a decrease in FMD from BL to the fourth hour (mean difference $=1.25 ; 95 \%$ CI $[0.22,2.28] ; p=.01)$. After adjustment for vessel diameter, there was a significant time effect $(p=.02)$, group effect $(p=.02)$, and Group $\times$ Time effect $(p=.03)$. One-way 

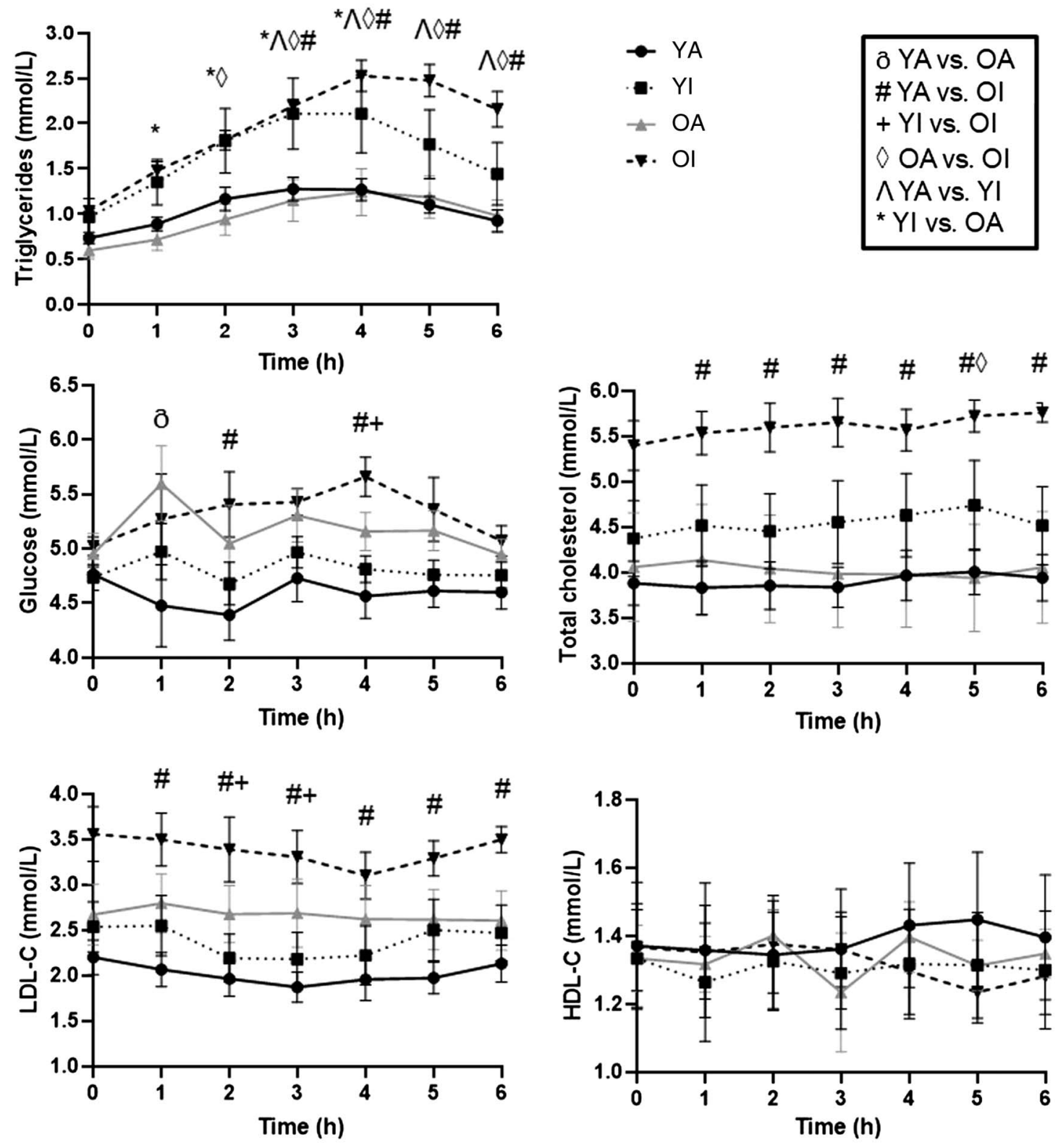

Figure 2 - Triglycerides, glucose, total cholesterol, LDL-C, and HDL-C were assessed at baseline/fasting (Time 0) and serially for 6 hr after the high-fat meal. Significant differences $(p<.05)$ at specific time points reflect the results of a two-way (Group $\times$ Time) repeated-measures ANOVA. Error bars reflect SEM. Total-C = total cholesterol; LDL-C = low-density lipoprotein cholesterol; HDL-C = high-density lipoprotein cholesterol; SEM = standard error of mean; ANOVA = analysis of variance; YA = younger active adults; $\mathrm{OA}=$ older active adults; $\mathrm{OI}=$ older inactive adults; $\mathrm{YI}=$ younger inactive adults.

ANOVA detected significant group differences in BL FMD (YA = $4.8 \pm 1.6, \mathrm{YI}=2.5 \pm 0.5, \mathrm{OA}=3.4 \pm 0.9, \mathrm{OI}=2.2 \pm 0.4 ; p<.001)$. At BL, the YA was greater than YI $(p=.008)$ and OA $(p=.003)$. Additionally, OA exhibited greater FMD than OI $(p=.04)$. The decrease in FMD from BL to the fourth hour across group remained after an adjustment for diameter (mean difference $=0.82 ; 95 \% \mathrm{CI}$ $[0.02,1.6] ; p=.04)$.

\section{Associations With Body Composition and HbA1c}

Associations between primary outcomes and body composition and $\mathrm{HbA} 1 \mathrm{C}$ are displayed in Table 3. After controlling for physical activity (steps per day) and age, VAT was positively associated with peak TG $(r=.43 ; p=.02)$, TG tAUC $(r=.38 ; p=.04)$, and TG
iAUC $(r=.50 ; p=.005)$. SMM was positively associated with TG iAUC $(r=.41 ; p=.03)$. Body mass index was positively correlated with FMD iAUC $(r=.44 ; p=.02)$. However, when interpreting these results with a Bonferroni correction to adjust for multiple correlations (adjusted $p$ value threshold $=.0014$ ), there were no significant correlations.

\section{Discussion}

Previous literature has demonstrated the negative implications of elevated postprandial TG in relation to CVD risk (Hokanson, 1998; McBride, 2007; Nordestgaard \& Varbo, 2014). Individuals typically consume meals frequently throughout the day, making PPL a physiologically relevant measurement. Several studies have 
separately examined the impact of age and physical activity on postprandial TG (Altena et al., 2004; Cassader et al., 1996; Emerson et al., 2018). Unlike in the study by Emerson et al. (2018), we found no significant difference in PPL by age when matched for physical activity. We believe this may be a result of the
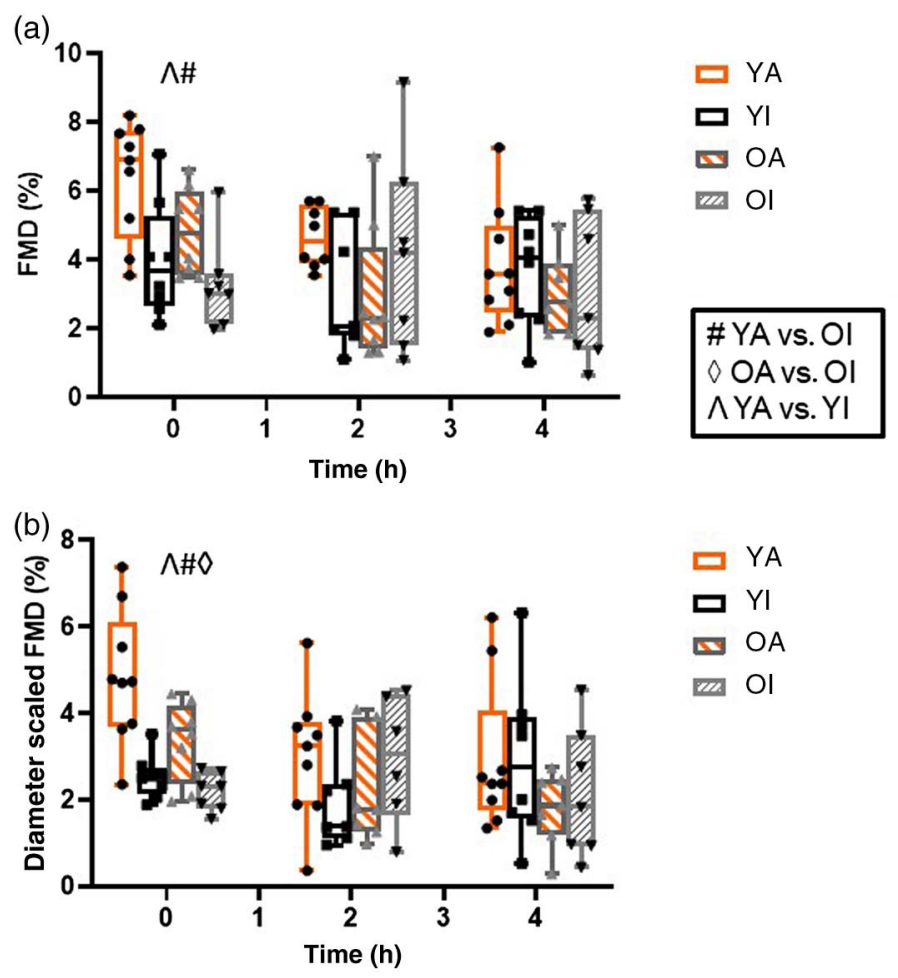

Figure 3 - Postprandial vascular function was measured at baseline/ fasting, $2 \mathrm{hr}$, and $4 \mathrm{hr}$ after the high-fat meal in which (a) represents the raw vascular function measurements as a percentage of dilation and (b) shows the percentage of dilation scaled to individual artery diameter. Significant differences $(p<.05)$ at specific time points reflect the results of a two-way $($ Group $\times$ Time) repeated-measures ANOVA. Error bars reflect SEM. SEM = standard error of mean; ANOVA = analysis of variance; $\mathrm{YA}=$ younger active adults; $\mathrm{OA}=$ older active adults; $\mathrm{OI}=$ older inactive adults; $\mathrm{YI}=$ younger inactive adults; FMD = flow-mediated dilation. higher overall steps per day that were achieved in the YA group in the previous study $(\mathrm{YA}=16,600 \pm 6,500)$ compared with the present study $(\mathrm{YA}=12,935 \pm 3,216)$. The YA individuals studied by Emerson et al. may have also been more habitually active than the YA in this study. Still, these findings point to the potent effects of regular physical activity on PPL, independent of age. Of note, the participants avoided exercise for $48 \mathrm{hr}$ prior to the HFM. Therefore, it is unlikely that the role of acute exercise is the explanation for group differences in PPL in our study.

There is clear evidence supporting the notion that older individuals exhibit an exaggerated PPL response compared with younger individuals (Cohn et al., 1988). However, it is unclear whether greater PPL seen in aging is simply an artifact of less physical activity compared with younger counterparts. As individuals age, physical exercise can become more challenging, increasing the likelihood of negative body compositional changes, such as a loss of muscle mass, increase in body fat percentage, and an increase in visceral adiposity. Together, a reduction in SMM and increased fat deposits have been associated with elevated PPL (Herd et al., 2001). In the present study, there were no differences in SMM between groups, although there were large differences in postprandial TG responses. Elevated visceral fat is associated with insulin resistance and dyslipidemia, causing exaggerated postprandial responses and, ultimately, an increased risk of CVD (Banerji et al., 1999; Jensen, 2008). Similar research assessing the impact of exercise on postprandial markers supports the contributing role of VAT in exaggerating PPL in both active and inactive individuals, wherein there is a positive relationship between VAT and PPL (Lee et al., 2013). Our data partially support this notion, as we found a potential positive correlation between VAT and numerous PPL indices across our total sample (Table 3). However, in the present study, there were no differences in VAT or body fat percentage between groups, preventing the conclusion that body fat was the primary driver of PPL responses. Furthermore, after manually correcting for multiple comparisons with a Bonferroni adjustment, none of the partial correlations were statistically significant. However, it should be noted that this correction increases the possibility of a Type II error in the present study. Taken together, our findings suggest that body composition may yet explain some, but certainly not all, of the variation in PPL due to age and physical activity status.

\section{Table 3 Partial Correlation of Body Composition and Glucose Control With Metabolic and Vascular Outcomes}

\begin{tabular}{|c|c|c|c|c|c|c|c|c|}
\hline & & TG fasted & TG peak & TG tAUC & TG iAUC & FMD fasted & FMD tAUC & FMD iAUC \\
\hline \multirow[t]{2}{*}{$\mathrm{BF}$} & $r$ & .31 & -.11 & .04 & -.20 & -.12 & .01 & .23 \\
\hline & $p$ & .11 & .58 & .83 & .30 & .57 & .94 & .25 \\
\hline \multirow[t]{2}{*}{ VAT } & $r$ & .12 & .43 & .38 & .50 & -.05 & .33 & .24 \\
\hline & $p$ & .55 & .02 & .04 & .005 & .81 & .09 & .23 \\
\hline \multirow[t]{2}{*}{ SMM } & $r$ & -.19 & .26 & .16 & .41 & -.07 & .20 & .16 \\
\hline & $p$ & .32 & .18 & .42 & .03 & .72 & .31 & .43 \\
\hline \multirow[t]{2}{*}{$\mathrm{HbA} 1 \mathrm{c}$} & $r$ & .08 & .18 & .17 & .20 & .33 & .29 & -.07 \\
\hline & $p$ & .69 & .36 & .39 & .31 & .09 & .13 & .74 \\
\hline \multirow[t]{2}{*}{ BMI } & $r$ & .06 & .23 & .22 & .30 & -.14 & .32 & .44 \\
\hline & $p$ & .77 & .24 & .25 & .11 & .47 & .10 & .02 \\
\hline
\end{tabular}

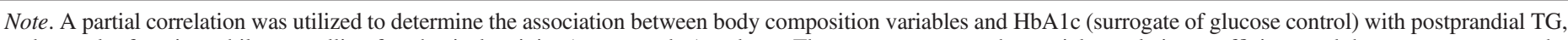

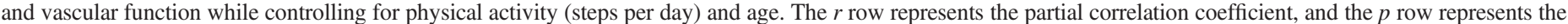

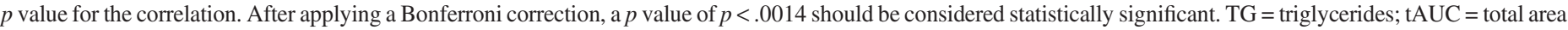

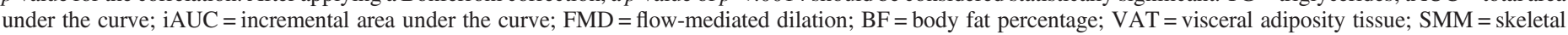
muscle mass; $\mathrm{HbA1c}=$ hemoglobin $\mathrm{A} 1 \mathrm{c} ; \mathrm{BMI}=$ body mass index. 
Vascular function is highly regarded as a predictor for CVD (Verma et al., 2003). Vascular function has been observed to decrease in response to an HFM (Ceriello et al., 2002; Kawano et al., 1999; Wallace et al., 2010). This relationship between PPL and FMD was partially supported by our findings, as there was a decrease in vascular function across groups after the HFM. Most notably, FMD reduction was more pronounced in the active groups. The greater decreases in vascular function observed in the active individuals could possibly be explained by a higher degree of function before the consumption of the HFM. Similarly, the lack of change in older and less active individuals might be due to preexisting, lower vascular function prior to the HFM. However, group differences in FMD during the postprandial period were not as large or distinct as those for PPL. Of note, this study did not control for menstrual cycle in the premenopausal females who participated, which may have contributed to some of the variability in the FMD measurements.

\section{Conclusion}

This study aimed to determine differences in postprandial metabolic and vascular outcomes in groups that differed by age and physical activity level, as well as explore factors that may explain group differences. Our data speak to the importance of physical activity in mediating TG responses to an HFM, which directly corresponds to the risk of CVD development. Moreover, the OA adults in our study exhibited a nearly identical PPL response to the YA adults, suggesting that physical activity level is more important in modifying PPL than age. With regard to vascular function, we observed HFMinduced decrements in FMD that were primarily observed in the active individuals. Although the findings for body composition were mixed, neither body composition nor HbAlc could fully explain the group differences in our study. Therefore, future studies should further investigate other physiological determinants of PPL, such as liver fat content, that are modified by age and physical activity level.

\section{Novelty Statement}

A high-fat meal induces acute vascular dysfunction, independent of age and physical activity level.

\section{Practice Application Statement}

Physical activity is a major driving factor for the reduction in postprandial triglycerides, even when considering age.

\section{Acknowledgments}

N.A. Koemel, E.A. Lucas, N.D.M. Jenkins, and S.R. Emerson contributed to project conceptualization and the data analysis. Participant recruitment and the data collection were conducted by N.A. Koemel, C.M. Sciarrillo, K.B. Bode, and M.D. Dixon. The first draft of the manuscript was written by N.A. Koemel and S.R. Emerson. All authors reviewed, edited, and approved the final manuscript. The authors declare that they have no conflict of interest.

\section{References}

Alipour, A., Elte, J.W.F., Van Zaanen, H.C.T., Rietveld, A.P., \& Cabezas, M.C. (2008). Novel aspects of postprandial lipemia in relation to atherosclerosis. Atherosclerosis Supplements, 9(2), 39-44. PubMed ID: 18595782 doi:10.1016/j.atherosclerosissup.2008.05.007

Altena, T.S., Michaelson, J.L., Ball, S.D., \& Thomas, T.R. (2004). Single sessions of intermittent and continuous exercise and postprandial lipemia. Medicine \& Science in Sports \& Exercise, 36(8), 1364-1371. PubMed ID: 15292745 doi:10.1249/01.mss.0000135793.43808.6c

Atkinson, G., Batterham, A.M., Thijssen, D.H., \& Green, D.J. (2013). A new approach to improve the specificity of flow-mediated dilation for indicating endothelial function in cardiovascular research. Journal of Hypertension, 31(2), 287-291. PubMed ID: 23169234 doi:10.1097/ HJH.0b013e32835b8164

Banerji, M.A., Faridi, N., Atluri, R., Chaiken, R.L., \& Lebovitz, H.E. (1999). Body composition, visceral fat, leptin, and insulin resistance in Asian Indian men. The Journal of Clinical Endocrinology \& Metabolism, 84(1), 137-144. PubMed ID: 9920074 doi:10.1210/ jcem.84.1.5371

Bansal, S., Buring, J.E., Rifai, N., Mora, S., Sacks, F.M., \& Ridker, P.M. (2007). Fasting compared with nonfasting triglycerides and risk of cardiovascular events in women. JAMA, 298(3), 309-316. PubMed ID: 17635891 doi:10.1001/jama.298.3.309

Blaak, E.E., Van Baak, M.A., \& Saris, W.H.M. (1999). $\beta$-Adrenergically stimulated fat oxidation is diminished in middle-aged compared to young subjects. The Journal of Clinical Endocrinology \& Metabolism, 84(10), 3764-3769. PubMed ID: 10523027 doi:10.1210/jcem. 84.10 .6043

Bosy-Westphal, A., Jensen, B., Braun, W., Pourhassan, M., Gallagher, D., \& Müller, M.J. (2017). Quantification of whole-body and segmental skeletal muscle mass using phase-sensitive 8-electrode medical bioelectrical impedance devices. European Journal of Clinical Nutrition, 71(9), 1061-1067. PubMed ID: 28327564 doi:10.1038/ ejcn.2017.27

Cassader, M., Gambino, R., Ruiu, G., Marena, S., Bodoni, P., \& Pagano, G. (1996). Postprandial triglyceride-rich lipoprotein changes in elderly and young subjects. Aging Clinical and Experimental Research, 8(6), 421-428. PubMed ID: 9061130 doi:10.1007/ BF03339605

Celermajer, D.S., Sorensen, K.E., Gooch, V.M., Spiegelhalter, D.J., Miller, O.I., Sullivan, I.D., ... Deanfield, J. (1992). Non-invasive detection of endothelial dysfunction in children and adults at risk of atherosclerosis. The Lancet, 340(8828), 1111-1115. PubMed ID: 1359209 doi:10.1016/0140-6736(92)93147-f

Ceriello, A., Taboga, C., Tonutti, L., Quagliaro, L., Piconi, L., Bais, B., ... Motz, E. (2002). Evidence for an independent and cumulative effect of postprandial hypertriglyceridemia and hyperglycemia on endothelial dysfunction and oxidative stress generation: Effects of short-and long-term simvastatin treatment. Circulation, 106(10), 1211-1218. PubMed ID: 12208795 doi:10.1161/01.cir.0000027569. $76671 . a 8$

Cohn, J.S., McNamara, J.R., Cohn, S.D., Ordovas, J.M., \& Schaefer, E.J. (1988). Postprandial plasma lipoprotein changes in human subjects of different ages. Journal of Lipid Research, 29(4), 469-479. PubMed ID: 3392464

Cree, M.G., Newcomer, B.R., Katsanos, C.S., Sheffield-Moore, M., Chinkes, D., Aarsland, A., ... Wolfe, R.R. (2004). Intramuscular and liver triglycerides are increased in the elderly. The Journal of Clinical Endocrinology \& Metabolism, 89(8), 3864-3871. PubMed ID: 15292319 doi:10.1210/jc.2003-031986

Devaraj, S., Wang-Polagruto, J., Polagruto, J., Keen, C.L., \& Jialal, I. (2008). High-fat, energy-dense, fast-food-style breakfast results in an increase in oxidative stress in metabolic syndrome. Metabolism, 57(6), 867-870. PubMed ID: 18502272 doi:10.1016/j.metabol. 2008.02.016 
Emerson, S.R., Kurti, S.P., Emerson, E.M., Cull, B.J., Casey, K., Haub, M.D., \& Rosenkranz, S.K. (2018). Postprandial metabolic responses differ by age group and physical activity level. The Journal of Nutrition, Health \& Aging, 22(1), 145-153. PubMed ID: 29300434 doi:10.1007/s12603-017-0956-6

Freese, E.C., Gist, N.H., \& Cureton, K.J. (2014). Effect of prior exercise on postprandial lipemia: An updated quantitative review. Journal of Applied Physiology, 116(1), 67-75. PubMed ID: 24201708 doi:10. 1152/japplphysiol.00623.2013

Ghafouri, K., Cooney, J., Bedford, D.K., Wilson, J., Caslake, M.J., \& Gill, J.M. (2015). Moderate exercise increases affinity of large very lowdensity lipoproteins for hydrolysis by lipoprotein lipase. The Journal of Clinical Endocrinology \& Metabolism, 100(6), 2205-2213. PubMed ID: 25867814 doi:10.1210/jc.2015-1196

Halcox, J.P., Schenke, W.H., Zalos, G.A., Mincemoyer, R.R., Prasad, A., Waclawiw, M., ... Quyyumi, A. (2002). Prognostic value of coronary vascular endothelial dysfunction. Circulation, 106(6), 653-658. PubMed ID: 12163423 doi:10.1161/01.cir.0000025404.78001.d8

Herd, S.L., Kiens, B., Boobis, L.H., \& Hardman, A.E. (2001). Moderate exercise, postprandial lipemia, and skeletal muscle lipoprotein lipase activity. Metabolism: Clinical and Experimental, 50(7), 756-762. PubMed ID: 11436177 doi:10.1053/meta.2001.24199

Hokanson, J.E. (1998). Hypertriglyceridemia as a cardiovascular risk factor. The American Journal of Cardiology, 81(4A), 7B-12B. PubMed ID: 9526807 doi:10.1016/s0002-9149(98)00031-9

Hyson, D., Rutledge, J.C., \& Berglund, L. (2003). Postprandial lipemia and cardiovascular disease. Current Atherosclerosis Reports, 5(6), 437-444. PubMed ID: 14525676 doi:10.1007/s11883-003-0033-y

Jackson, K.G., Poppitt, S.D., \& Minihane, A.M. (2012). Postprandial lipemia and cardiovascular disease risk: Interrelationships between dietary, physiological and genetic determinants. Atherosclerosis, 220(1), 22-33. PubMed ID: 21955695 doi:10.1016/j. atherosclerosis.2011.08.012

Jensen M.D. (2008). Role of body fat distribution and the metabolic complications of obesity. The Journal of Clinical Endocrinology and Metabolism, 93(11, Suppl. 1), S57-S63. PubMed ID: 18987271 doi:10.1210/jc.2008-1585

Katsanos, C.S. (2014). Clinical considerations and mechanistic determinants of postprandial lipemia in older adults. Advances in Nutrition, 5(3), 226-234. PubMed ID: 24829469 doi:10.3945/an.113.004903

Kawano, H., Motoyama, T., Hirashima, O., Hirai, N., Miyao, Y., Sakamoto, T., ... Yasue, H. (1999). Hyperglycemia rapidly suppresses flow-mediated endothelium-dependent vasodilation of brachial artery. Journal of the American College of Cardiology, 34(1), 146154. PubMed ID: 10400004 doi:10.1016/s0735-1097(99)00168-0

Lee, S., Burns, S.F., White, D., Kuk, J.L., \& Arslanian, S. (2013). Effects of acute exercise on postprandial triglyceride response after a high-fat meal in overweight black and white adolescents. International journal of obesity (2005), 37(7), 966-971. PubMed ID: 23507997 doi:10. 1038/ijo.2013.29

Marchesi, S., Lupattelli, G., Schillaci, G., Pirro, M., Siepi, D., Roscini, A.R., ... Mannarino, E. (2000). Impaired flow-mediated vasoactivity during post-prandial phase in young healthy men. Atherosclerosis, 153(2), 397-402. PubMed ID: 11164429 doi:10.1016/s0021-91 50(00)00415-9

McBride, P.E. (2007). Triglycerides and risk for coronary heart disease. JAMA, 298(3), 336-338. PubMed ID: 17635897 doi:10.1001/jama. 298.3.336

Nordestgaard, B.G., \& Varbo, A. (2014). Triglycerides and cardiovascular disease. The Lancet, 384(9943), 626-635. PubMed ID: 25131982 doi:10.1016/S0140-6736(14)61177-6

Peddie, M.C., Rehrer, N.J., \& Perry, T.L. (2012). Physical activity and postprandial lipidemia: Are energy expenditure and lipoprotein lipase activity the real modulators of the positive effect? Progress in Lipid Research, 51(1), 11-22. PubMed ID: 22123195 doi:10.1016/j. plipres.2011.11.002

Pierce, G.L., Eskurza, I., Walker, A.E., Fay, T.N., \& Seals, D.R. (2011). Sex-specific effects of habitual aerobic exercise on brachial artery flow-mediated dilation in middle-aged and older adults. Clinical Science, 120(1), 13-23. PubMed ID: 20642454 doi:10.1042/ CS20100174

Piercy, K.L., Troiano, R.P., Ballard, R.M., Carlson, S.A., Fulton, J.E., Galuska, D.A., ... Olson, R.D. (2018). The physical activity guidelines for Americans. JAMA, 320(19), 2020-2028. PubMed ID: 30418471 doi:10.1001/jama.2018.14854

Stewart, J., Manmathan, G., \& Wilkinson, P. (2017). Primary prevention of cardiovascular disease: A review of contemporary guidance and literature. JRSM Cardiovascular Disease, 6, 2048 004016687211. PubMed ID: 28286646 doi:10.1177/204800 4016687211

Talayero, B.G., \& Sacks, F.M. (2011). The role of triglycerides in atherosclerosis. Current Cardiology Reports, 13(6), 544. PubMed ID: 21968696 doi:10.1007/s11886-011-0220-3

Verma, S., Buchanan, M.R., \& Anderson, T.J. (2003). Endothelial function testing as a biomarker of vascular disease. Circulation, 108(17), 2054-2059. PubMed ID: 14581384 doi:10.1161/01.CIR. 0000089191.72957.ED

Vogel, R.A. (1997). Coronary risk factors, endothelial function, and atherosclerosis: A review. Clinical Cardiology, 20(5), 426-432. PubMed ID: 9134272 doi:10.1002/clc.4960200505

Wallace, J.P., Johnson, B., Padilla, J., \& Mather, K. (2010). Postprandial lipaemia, oxidative stress and endothelial function: A review. International Journal of Clinical Practice, 64(3), 389-403. PubMed ID: 20456177 doi:10.1111/j.1742-1241.2009.02146.x 